\title{
Polymer Optical Fibers as Gas Sensors
}

\author{
Marko Dorrestijn, ${ }^{1}$ Agathe Camerlo, ${ }^{1}$ Susanne Widmer, ${ }^{1}$ René M. Rossi, ${ }^{1}$ Špela Korent Urek, ${ }^{2}$ Branka \\ Viltužnik, ${ }^{2}$ Alenka Ribič, ${ }^{2}$ Alexandra Lobnik, ${ }^{2}$ Lukas J. Scherer ${ }^{1}$ \\ ${ }^{1}$ Empa, Swiss Federal Laboratories for Materials Science \\ and Technology, Laboratory for Protection and Physiology, \\ Lerchenfeldstr. 5, St. Gallen, Switzerland, \\ Correspondence: marko.dorrestijn@empa.ch \\ ${ }^{2}$ IOS, Institute for environmental protection and sensors, Ltd., \\ Sedež Beloruska ulica 7, Maribor, Slovenia
}

\begin{abstract}
Gas sensors based on optical fibers are attractive alternatives to the presently available sensors. Integration of sensor fibers into protective clothing would significantly increase sensor wearability. We present a gas sensing polymer optical fiber (POF) that is flexible enough to be stitched into textiles. Also, the polymer is UV-transparent to allow for fluorescent dyes. By using a porous sol-gel matrix, response times down to $1 \mathrm{~s}$ were achieved.
\end{abstract}

Key words: gas sensing, optical fibers, cyclo-olefin polymer, sol-gel, ormosil, textiles

\section{Introduction}

For gas sensing, different optical systems based on the evanescent wave absorption along optical fibers have been reported [1-4]. In such a system, a dye - which responds to the presence of a target molecule - is incorporated in a polymer or sol-gel matrix.

However, glass fibers and common sol-gels are too brittle to be stitched into protective clothing. Also, UV transmission is problematic in glass fibers, which limits the use of fluorescent dyes.

Here, we present a flexible polymer optical fiber (POF) based gas sensor. The fiber is coated with a porous and flexible sol-gel for quick response times. For demonstration purposes, the sol-gel was loaded with $\mathrm{pH}$-sensitive dyes. To allow the dye to be fluorescent, the polymer was selected for transparency in the near-UV range.

\section{Experimental}

The fiber cores were produced by melt spinning of cyclo-olefin polymer (COP) in a pilot plant. The fibers were dip-coated into sol-gel. The solgel was based on tetraethyl orthosilicate, which was partially replaced by organically modified silicates (ormosil). The amount and type of the latter allowed a tunable degree of flexibility to the sol-gel.

A mixture of two $\mathrm{pH}$-sensitive fluorescent dyes, fluorescein and coumarin (7-diethylamino-4- methylcoumarin), was used as chemical indicator in the sol-gel matrix. Fluorescence intensities were measured using an integrating sphere connected to a photomultiplier.

\section{Results \& Discussion}

The response of the flexible polymer/sol-gel system was tested towards hydrochloric acid $(\mathrm{HCl})$ and ammonia $\left(\mathrm{NH}_{3}\right)$ vapors (Fig. 1). The response times were fast, typically on the order of 1 second.

a)

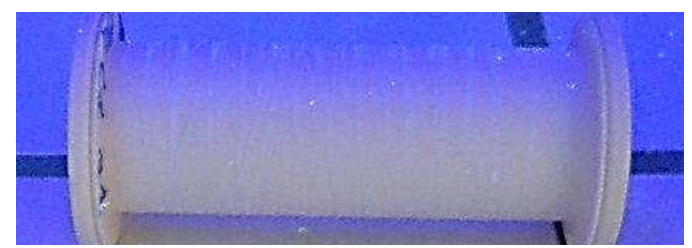

b)

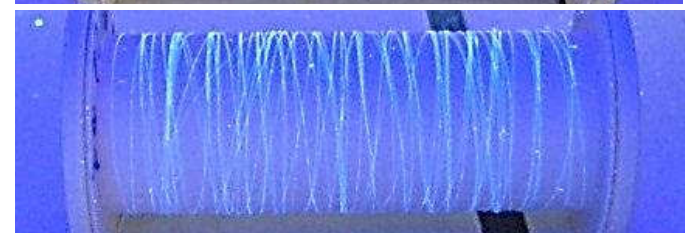

Fig. 1. POF after exposure to $\mathrm{HCl}$ (a) and $\mathrm{NH}_{3}$ (b) vapor. The bobbin was illuminated with a UV lamp (366 nm).

The reproducibility of such a sensor system was tested by alternating exposure to $\mathrm{HCl}$ and $\mathrm{NH}_{3}$ vapors for 30 cycles (Fig. 2). No sensor drift was observed. However, some variability in the fluorescence intensity was seen, which may be due variations in the air flow between the 
liquid and the sensor. The fiber sensors were successfully stitched into textiles.

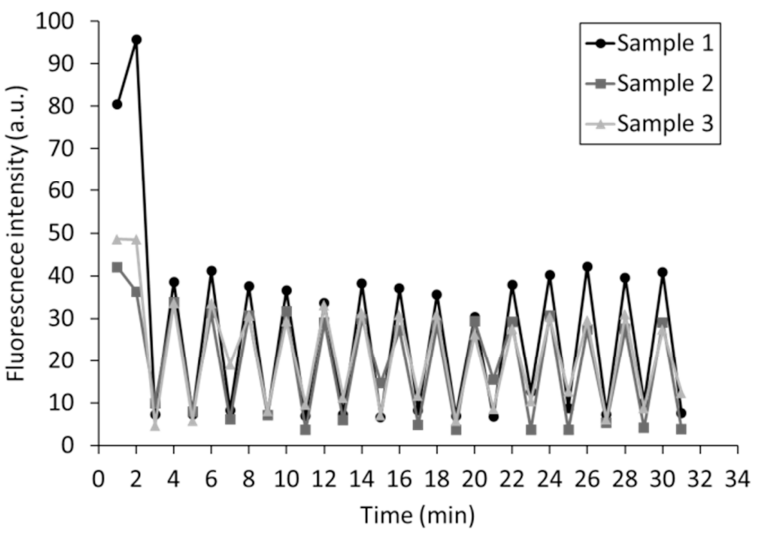

Fig. 2. Fluorescence intensity after exposure to vapors. The vapors were alternated between $\mathrm{HCl}$ (odd time values) and $\mathrm{NH}_{3}$ (even time values). Each exposure lasted 1 minute. Data at time $1 \mathrm{~min}$. were without exposure.

\section{Conclusions}

A flexible polymer optical fiber (POF) with solgel coating was developed for gas sensing. Gas detection was demonstrated using $\mathrm{pH}$-sensitive fluorescent dyes vs. hydrochloric acid $(\mathrm{HCl})$ and ammonia $\left(\mathrm{NH}_{3}\right)$. No degradation of the sensor was observed for at least 30 cycles.
The integration of such fibers into textiles will lead to sensors of a significantly higher wearability than was thus far possible. We foresee that this platform technology will be extended to detection of toxic industrial chemicals (TICs) and chemical warfare agents (CWAs) to protect personnel in the chemical industry and first responders.

\section{Acknowledgements}

We gratefully thank B. Wüst for melt spinning the fibers.

\section{References}

[1] S. T. Lee, et al, Journal of Optics A-Pure and Applied Optics 3, 355 (2001); doi:10.1088/1464$4258 / 3 / 5 / 307$

[2] M. Beshay, et al, Proc. of SPIE Vol. 6954, 69540F-1 (2008); doi:10.1117/12.778117

[3] S. R. Cordero, et al, Proc. of SPIE Vol. 6378. 63780U-1 (2006); doi:10.1117/12.685433

[4] B. D. Gupta, S. Sharma, Optics Communications 154, 282 (1998); doi:10.1016/S00304018(98)00321-6 